its rigidity might renker pnrturition difficult and laborions. That cases may possibly occur where such practice might be safe and expedient, I do not mean to assert; but out of upwards of $\mathbf{8 0 0}$ obstetric cases, I have never yet encountered one in which $I$ have conceived that it was indicated. When the os uteri has become fully dilated, and no malformation of the pelvis exists, rigidity of the perinæum will seldom long retard delivery. Cases, indeed, frequently occur, particularly in robust and plethoric females, of middle age, who are parturient for the first time, in which the fourchette is very rigrid and unyielding; but this state is seldom of long continuance after the complete dilatation of the os uteri, provided the pains be sufficiently powerful. I have met with a dozen of cases in my practice, where delivery has been retarded for a few hours by the extreme rigidity of the perinaum. In such cases, after the relaxation of the bowels by castor oil, or an enema, I have given a full dose of tincture of opium; and if my patient has been plethoric, or febrile excitement has been present, I have abstracted blood pleno rivo. This treatment has nerer yet failed me.

Though the practice recommended by $\mathrm{Mr}$. Rolland might, in some rare cases, be advisable, it would, I apprehend, be scarcely ever submitted to, in consequence of the timidity of females respecting cutting instruments, and wo to the obstetric wight who would, without an acknowledged necessity, and the highest sanction of his professional brethren, perform such an operation! To him, I apprehend, would be applicable the Hudibrastic lines,-

"Ah! me, what perils do environ

The man who meddles with cold iron."

Your correspondent, I conceive, thinks too lightly of laceration of the perinæum, as, when ex tensive, it is an occurrence which is productive to the patient not only of much personal discomfort and annoyance, but frequently also of connubial unhappiness; and to the accoucheur it is highly discreditable, as it may, in almost every instance, by judicious management, be prevented. I remain, Sir, your obedient servant,

J. Kinnier, M.D.

East-rioad, City-road, Nov, 30.

\section{SECTION OF THE PERINEUM IN LABOUR.}

\section{To the Editor of The LanceT.}

SIR :-Your correspondent, Mr. Rolland, wishes to direct the attention of the profession to a practice recommended by himself ; and as it might be adopted by the unwary whose qualification to judge of the matter should not surpass his own, 1 hope he will not be offeuded by the comment he invites.

He gravely advises the section of the perinæum in labour, on the supposition that the principal resistance to the expulsion of the foetus is offered by that structure, ard that the greater proportion of parturient su: fering is a consequence of such impediment. He says, " the lubricated and spongy uterus gives way on the first or second impulse,""That when the perinæum has been torn, no bad effects have occurred, only from ima: ginary fears" - When the head of the child hangs for a longer time than is common for expulsion, I should recommend the use of a bistoury, the division with which wonld be attended with immediate relief,-if the per. son be young the happiest results would happen; certainly it would prevent the pe. rinæum from being torn, lessen danger in future labour's, and expedite the contraction of the uterus." The whole of these data are incorrect, and the inference is pernicious, the only exception being the somewhat non. apparent truth, that "cutting the perinxum would prevent its laceration!"

It were somewhat impertinent, because superfluous, to affect to initiate your readers in the elements known to nearly all, there. fore a detailed refutation of Mr. Rolland's creed is spared; but should he adopt the practice which he recommends, or should another follow it, he may beassured that he could not find his justification in reason of authority, and that he would, in the event of an action at law, be certainly and justly amer. ced in heavy damages formala-praxis. Yours obediently,

$$
\text { Nov, 30, } 1836 .
$$

W. A. WaLroró,

\section{TWIN BIRTHS.-MR. HUNTER' COMMUNICATION.}

\section{To the Edi:or of The Laxcer.}

Srr:-In my letter of the 7 th ultimo, I neglected to include two twin cases which were attended by me during the current year, and as that omission affects ny com munication in a statistical point of riew, will thank you to correct the error in the following terms:-66 of 1571 cases which have happened in my own practice, 19 have been twin cases. Of these, 7 were firs cases of pregnancy, and 4 of them occurred in 1833 , the number of births in that yeal having been 106." In the ninth line from the bottom of my letter would is incorrectl printed for could. I am, Sir, your obedien serrant,

Margate, Dec. Ist, 1836.

* As a military surgeon the presumption is re sonable, that his opportunities of obstetric impror ment must hare been comparatively rare. 